\title{
Disciplinary Sanctions in English Premiership Football: Is There a Racial Dimension?
}

\author{
Barry Reilly and Robert Witt*
}

\begin{abstract}
This paper assesses the evidence for racial differences in the accumulation of disciplinary sanctions in professional football using data drawn from five recent seasons of the English Premiership. A relatively rich data source was used to construct a unique dataset for this study. The data have the significant advantage of being able to identify, inter alia, the player's age, club, field position, number of games played, time played per game, and the number of disciplinary cards received. These data were merged with data from other sources to identify the racial affiliation of the player across four separate categories (viz., white, black, mixed race, and Asian). On the basis of our preferred econometric approach, no evidence of unfair treatment of players from racial minority groups in the accumulation of disciplinary cards.
\end{abstract}

Keywords: Poisson Binomial panel; Negative Binomial panel; Linear Fixed Effects; English Premiership football; disciplinary cards.

Acknowledgement: The authors are grateful to the Nuffield Foundation for financial support (under award SGS/36059) and to Kalle Hirvonen for excellent research assistance.

Reilly: Department of Economics, University of Sussex, Brighton, BN1 9RF, UK.

*Witt: Department of Economics, University of Surrey, Guildford, GU2 7XH, UK.

This Draft: December 2009 


\section{Introduction}

There exists an extensive empirical literature on racial discrimination in professional team sports in the United States (US) with one of the most intensively researched areas focused on salary discrimination. The comprehensive reviews of Kahn $(1991 ; 2000)$ and Rosen and Sanderson (2001) report little empirical evidence in support of racial pay discrimination against non-whites in the labour markets for professional football and baseball in more recent times, though work by Gius and Johnson (2000) suggests evidence of a reverse discrimination against whites in the former sport. Soccer is the most popular team sport in Europe and Frick (2007) notes that the market values of the largest European professional soccer clubs are comparable in magnitude to the most valuable franchises in US team sports. In contrast to research available for the US, the theme of racial discrimination within professional football in Europe has attracted limited research interest due in large part to restrictions on access to salary data ${ }^{1}$, and this is particularly the case for England. An exception is provided by the work of Szymanski (2000), who examined racial salary discrimination in the English football league indirectly through exploiting wage bill information for a panel of 39 clubs between the 1978/9 and 1992/3 seasons. The study found that clubs with an above average proportion of black players tended to perform, on average and ceteris paribus, better than expected given their aggregate wage bills. However, the author found no evidence of consumer or fan-based discrimination (see Preston and Szymanski (2000)). On a related topic, Reilly and Witt (1995) and Medcalfe (2008), using data on the transfer fees that clubs pay for their players in the English league, detected no unequal treatment with respect to player race once account is taken of an array of player and performance characteristics. In contrast, Goddard and Wilson (2009) using labour market transitions to test for racial discrimination in English professional football found empirical support for a form of hiring discrimination that affected less talented black players compared to comparably less talented white players.

There is a separate strand of literature on the use of disciplinary sanctions in professional soccer. For example, research has considered the effect of player dismissal on match outcomes (e.g., Ridder et al. (1994)), and the determinants of disciplinary cards received by players within a crime-punishment context (e.g., Witt (2005)). Dawson et al. (2007) analyse patterns in the incidence of cards dispensed against players in the English Premier League over the period 1996 to 2003 and find that, inter alia, referees are inclined to award more

\footnotetext{
${ }^{1}$ Lucifora and Simmons (2002) provide an exception using data for the Italy’s Seria A league.
} 
disciplinary points against the away rather than the home team, a result they attribute to a refereeing bias favouring the home team. Garicano et al. (2005), using data from Spain's La Liga, and Dohmen (2008), using data from the German Bundesliga, corroborate the English evidence of a referee bias favouring home teams. The latter two studies exploit the theoretical work of Ackerlof (1980) and Bernheim (1994) in situating their analyses within a framework of social pressure where the crowd of match attendees exert a collective influence on a referee's private (and intended impartial) behaviour. Rickman and Witt (2008), using a quasi-experimental framework, investigated the impact of professional referees on a commonly used measure of referee bias (i.e., the length of injury time in close matches) and found that referees exercised a degree of favouritism prior to the advent of professionalism but not thereafter.

In most professional team sports players and referees repeatedly interact in, what at times, are highly-charged and intensely competitive environments. Referees are generally required to make split-second decisions that permit the possibility of the type of bias evidenced above, but does not preclude a more insidious form of a bias motivated by race. In the context of the English Premiership all referees are currently drawn from the white ethnic group, so the possibility of a non-white refereeing bias is not an implausible proposition. ${ }^{2}$ The exercise of such bias requires no intentional racial animus on the part of a referee and can occur even among those actively trying to avoid it. The notion of an unintended racism finds support in a growing literature on the role of implicit discrimination based on what social psychologists define as unconscious mental associations between a target (e.g., a black person) and an attribute (e.g., violence). ${ }^{3}$ This literature emphasizes stereotyping through such implicit associations, and Payne (2006) and Payne et al. (2002) highlight the finding, using laboratory experimental evidence on the 'weapon bias' theme, that an individual's propensity to implicitly stereotype increases with the need to make rapid or split-second decisions. ${ }^{4}$ It is well documented elsewhere that the experience of many black and mixed race players within

\footnotetext{
${ }^{2}$ Professional Game Match Officials Limited (PGMOL) was formed in 2001 to provide match officials for all professional football matches played in England and is responsible for the training, development, assessment and monitoring of all referees in the professional game including the sub-set of professional referees who officiate at English Premiership games. There are 31 professional referees officiating at the games covered by our dataset.

${ }_{4}^{3}$ See Bertrand et al. (2005) for a brief review of the economics literature on this topic.

${ }^{4}$ The laboratory experiment required participants to make visual discriminations between guns and more harmless objects. A human face is randomly flashed (black in some cases and white in others) just before each object appeared and, in one version of the experiment, participants are required to make decisions within half a second. Respondents were more likely 'to detect guns' in the presence of a black than a white face when halfsecond decisions were required.
} 
the professional game in England, particularly prior to the mid-1990s, was a difficult and unpleasant one, and their contribution at times the subject of a gratuitous and excessive stereotyping. ${ }^{5}$

The referees operating in the English Premiership, however, are subject to a very high degree of scrutiny that may act to attenuate either explicit or implicit forms of racial bias. They are monitored at each game by a match assessor who grades their match day performance and are required to attend fortnightly meetings at which their performances are evaluated. In addition, referees are also required to operate within the full glare of the print and broadcast media with televised Premiership games in particular ensuring that the decisions of referees are subject to the closest analysis. ${ }^{6}$

The primary purpose of the current study is to integrate two existing but hitherto separate strands on race treatment and punishment within a professional team sports context, and test for the presence of racial discrimination in the application of disciplinary sanctions in English Premiership football. ${ }^{7}$ To the authors' knowledge, this type of issue has been the subject of only one study to date in the context of a professional team sport with Price and Wolfers (2007) providing an application to professional basketball in the US. The authors find that, conditioning on player, referee and game-specific fixed effects, more personal fouls are called against players of a particular racial group when the games are officiated by opposite compared to own-race refereeing crews. The magnitude of the racial biases is found to be sufficiently large to influence game outcomes. The findings concur with other evidence of own-race preferences drawn from the non-sports literature for the US that may reflect the role of implicit discrimination (for example, see Antonovics and Knight (2005) and Donohue and

5 A good illustration of this type of racial stereotyping is provided by the controversial comments of Ron Noades who, in 1991 when chairman of Crystal Palace (then a top-tier side), suggested that '[t]he black players at this club lend the side a lot of skill and flair, but you also need white players in there to balance things up and give the team some brains and some commonsense.'

\footnotetext{
${ }^{6}$ A professional referee officiating in the English Premiership earns about $£ 49,000$ per annum plus a match fee, considerably less than the poorest paid professional footballer plying his trade in the English Premiership.

${ }^{7}$ Becker's (1971) treatise on the economics of discrimination could provide an alternative theoretical framework within which our analysis could be situated in the sense that Premiership referees could exhibit, on average, a taste for discrimination against opposite race (or non-white) players. However, we do not find such reasoning totally plausible and prefer to interpret refereeing decisions as subject to the potential influence of unintended or implicit discrimination.
} 
Levitt (2001) for applications to policing behaviour; see Stauffer and Buckley (2005) and Stoll Raphael and Holzer (2004) for applications in the field of human resources).

The approach adopted in the current paper, while focusing on both a different professional team sport and country, differs from that undertaken by Price and Wolfers (2007) in a number of distinct ways. First, it treats the player rather than the game (or quarter) as the primary unit of observation and follows the player over a maximum of five playing seasons. Second, given that all but one of the referees in the Premiership over the period covered by our data is white, the own-race bias refers to a preference for the white ethnic group only and does not permit an examination of own-race preference towards non-white players, as permissible with the Price and Wolfers (2007) data. $^{8}$ For example, our data does not allow the type of suggestive difference-in-difference approach that motivated some the analysis reported in their study. Third, in the context of association football, the referee retains the ultimate authority in issuing a disciplinary sanction, so the racial composition of the officiating fourman team at a Premiership fixture, in contrast to the case of the National Basketball Association (NBA), is irrelevant to the sanction outcome. Fourth, the analysis focuses on the formal disciplinary sanction of receiving a card rather than on a player's foul count as in Price and Wolfers (2007). In our analysis, the player foul count provides an input into the outcome process of receiving a disciplinary card, and while it is acknowledged that it may also be subject to the effects of implicit racial bias it does not provide the primary disciplinary outcome measure for our analysis. ${ }^{9}$ In contrast to a foul call, the display of a yellow card occurs after some reflection on the part of the referee and is arguably not a decision made within a split-second timing frame. Therefore, it could be that the tendency towards racial stereotyping may be attenuated in the use of this sanction. Nevertheless, while recognising the potential for a reduced stereotyping in dispensing a yellow card compared to penalising a player for a foul, we take the view that the majority of fouls committed in a soccer game are generally less costly to the offending team than fouls committed in a basketball match and generally have a less adverse effect on a game outcome. This follows logically from the dimensional difference in the field/court of play between the two sports. In addition, we take the reasonable view that the yellow card provides the more potent punitive

\footnotetext{
${ }^{8}$ The only black referee to officiate at Premiership games was Uriah Rennie, who retired at the end of the $2004 / 5$ season and is thus absent from three of the five seasons covered in our analysis.

${ }^{9}$ The issue here is similar to what presents in the analysis of pay discrimination by race where endowment differences relating to say human capital measures are treated as 'justified' even though they may reflect a discriminatory process that operates prior to labour market entry.
} 
sanction and thus has the potential to influence a game outcome. For this reason the disciplinary card provides the central focus for our analysis.

The receipt of a disciplinary card in professional football can matter for a number of reasons. It can have implications for player behaviour on the pitch, perhaps rendering a player more cautious when coming into contact with an opposition player, thus potentially influencing the outcome of a particular game. It can also have implications for a player's remuneration if an element of a club's pay structure is performance related. Clubs with a larger number of nonwhite players may be disadvantaged on the field of play and performance-related earnings of non-white players may thus be adversely affected. And whether there is a racial dimension in the application of disciplinary sanctions in professional football matters for social reasons since any racially motivated behaviour is inimical to social cohesion, and this is particularly apposite if the behaviour is evident within a high profile sport like Premiership football, the clubs of which have an annual aggregate turnover well in excess of a billion pounds.

In order to interrogate the relationship between race and disciplinary sanctions, the current paper uses a unique and detailed individual-level dataset on players for all games played in the English Premiership covering five recent league seasons from 2003/4 to 2007/8. The key emphasis in this paper is the relationship between the race of a player and the number of disciplinary sanctions served over a playing season as measured by the accumulation of yellow cards. ${ }^{10}$ If we allow controls for a variety of match performance indicators and player characteristics, then any ceteris paribus differential in disciplinary cards accumulated over a playing season by racial group could be taken to reflect the average effect of a racial bias among referees. The structure of the paper is now outlined. The next section discusses the dataset to be used and this is then followed by a section that details the econometric methodology. The empirical results provide the penultimate section and a final section offers some concluding remarks.

\section{Data}

The primary data source used in the analysis is provided by OPTA Sportsdata and provides for each player their club affiliation, age, primary field position, time at each club, number of

\footnotetext{
${ }^{10}$ The more serious sanction associated with the use of red cards by referees (i.e., a player sending-off) is not the subject of investigation in this study given it is a much rarer event and requires a different modelling approach.
} 
appearances and the duration in minutes of each appearance. The data also include the number of penalised fouls committed by the player per game and the number of yellow (and red) cards received. The racial classification used for each player is restricted to four categories (viz., white, black, mixed race, and Asian). The assignment of each player to these groups was informed by the inspection of colour photographs using information from club websites. This approach implicitly assumes that any racial bias directed towards an individual player is motivated by their phenotype rather than their genotype. ${ }^{11}$

The player represents the unit of observation and players are drawn from the 30 clubs that featured in the English Premiership over the relevant five-season period. The sample of professional players used is conditioned on those that made at least one appearance of whatever duration for their respective clubs in a Premiership league game. The sanction outcome is provided by the total number of yellow cards received by a player in a given season. The seasonal cross-sections are pooled over time to construct a panel. The resultant data comprise an unbalanced panel of 2,634 observations on 1,162 players. About one-fifth of the sample features for just one season in the panel, while close to one-third are represented in all five seasons. The average number of observations per player in the panel is 2.3 .

Table 1 provides a description of the variables used and some selected summary statistics, which are reported for both the overall panel as well as averaged by player. The average number of yellow cards issued per player was just under two but the outcome exhibits a large standard deviation. Approximately $30 \%$ of players who played in Premiership games over the relevant period did not receive a yellow card and this has implications for the econometric modelling discussed in the next section. The average player in the sample played about 63 minutes per game, and the average foul count per player was about 17 but again this has a very large standard deviation. The average player at the start of the season was aged 26 , and the distribution of players across field positions is as expected with midfielders and defenders dominating the sample. The majority of players have English as their native language and over two-thirds are white. A very small number of Asian players, largely originating from China and Korea, feature in the Premiership over the relevant period and over one-quarter of players are classified as either black or mixed race depending on skin tone.

\footnotetext{
${ }^{11}$ Goldsmith et al. (2006) provide a useful discussion of this distinction in their analysis of the relationship between wages and skin shade in the US.
} 


\section{Table 1 about here}

We now use these data to examine the raw differences in foul and card counts across two broadly defined racial groups. For the purpose of this preliminary exercise we allocate players to either a 'white' or a 'non-white' group. A set of parametric and non-parametric tests are used to determine if there are any statistical differences across these two race groups in mean and median outcomes both for each season and pooled across all five seasons. Table 2 reports the findings for the fouls. The average point estimates for the foul counts are higher for the non-white players and this is found to be statistically significant at a conventional level using both the pooled data and that for the 2006/2007 season. A similar exercise is conducted using the disciplinary card counts. In all cases the point estimate for the average card count for the 'white' group is higher than the 'non-white' group, though in no case is the difference found to be statistically significant at a $5 \%$ level or better using any of the three test statistics. Thus, non-white players are penalised more than white players but receive on average fewer disciplinary cards. However, the card count differentials represent raw differences that do not control for key characteristics that may determine sanction outcomes (e.g., foul count, time played and player field position). A more thorough analysis requires use of econometric techniques, which are the subject of the next section.

\section{Tables 2 \& 3 about here}

\section{Econometric Methodology}

In order to control for player-specific omitted factors in the estimation of the sanction outcome model, the panel nature of the data is exploited. Assuming the omitted factors vary across individual players but are fixed over the short time period available, a possible approach is provided by the standard linear regression fixed effects panel estimator. This allows for a correlation between fixed effects and the covariates but there is no requirement to specify a parametric distribution for the fixed effects. All observations are useable within this framework but the data for players who are in the panel for just one year do not provide any within-group variation and therefore make no contribution to the computation of the estimates for the included covariates. However, fixed effects for all players are retrievable and available for further empirical analysis. This is advantageous in the current application given a primary interest in the role of the time invariant factor of race which is not directly 
identifiable within this framework as it is absorbed within the individual player's fixed effect. The linear fixed effects panel model is specified as follows:

$y_{i t}=\alpha_{i}+\mathbf{x}_{\text {it }}^{\prime} \boldsymbol{\beta}+u_{i t}$

where $\mathrm{u}_{\mathrm{it}} \sim \operatorname{iid}\left(0, \sigma^{2}\right)$ and $\mathrm{i}=1,2, \ldots \ldots, \mathrm{n}$ individual-level observations on players, and $\mathrm{t}=$ $1,2, \ldots \ldots . ., \mathrm{T}$ time series observations. In the current application, $\mathrm{y}_{\mathrm{it}}$ represents the number of yellow cards issued to player $\mathrm{i}$ in time period $\mathrm{t}$ (where $\mathrm{t}$ is a given season), $\mathbf{x}_{\mathrm{it}}$ is a vector of $\mathrm{k}$ covariates that vary both across individual players and over time (or season), and $\alpha_{i}$ represents the fixed effects for the $i^{\text {th }}$ player. The estimation procedure transforms the data as deviations from group means, a transformation which sweeps out the individual specific fixed effects in this linear context. The $\mathrm{i}^{\text {th }}$ fixed effect can be retrieved post-estimation using the relationship:

$\hat{\alpha}_{i}=\bar{y}_{i}-\overline{\mathbf{x}}_{i}^{\prime} \hat{\boldsymbol{\beta}}$

where the circumflexes denote the relevant coefficient estimates and the bars the mean values for the $i^{\text {th }}$ groups (i.e., the players). The $\mathrm{n}$ fixed effect estimates are then used in a secondstage regression as follows:

$$
\hat{\alpha}_{i}=\mu+z_{i}^{\prime} \theta+v_{i}
$$

where $\mathrm{i}=1,2, \ldots \ldots, \mathrm{n}$ and $\mathbf{z}_{\mathrm{i}}$ is a vector of time invariant factors including player position and race. This second stage regression can be estimated by ordinary least squares procedures. An econometrically efficient procedure, however, exploits the sampling variances obtained for the individual fixed effects within a weighted least squares (WLS) framework. This serves the purpose of attaching a greater weight in estimation to the most precisely estimated fixed effects. The sampling variance for the $\mathrm{i}^{\text {th }}$ fixed effect is computed as:

$\operatorname{var}\left(\hat{\alpha}_{i}\right)=\frac{s^{2}}{n_{i}}+\overline{\mathbf{x}}_{i}^{\prime} \mathrm{V}(\hat{\boldsymbol{\beta}}) \overline{\mathbf{x}_{i}}$

where $\overline{\mathbf{x}}_{i}$ is defined as above, $\mathrm{s}^{2}$ is the estimated variance from the original fixed effects regression model in [1], $\mathrm{n}_{\mathrm{i}}$ is the number of observations in the $\mathrm{i}^{\text {th }} \operatorname{group}, \mathrm{V}(\hat{\boldsymbol{\beta}})$ is the estimated variance-covariance matrix corresponding to the set of covariates used in the linear panel regression. 
A problem with using the linear panel approach is that it assumes the dependent variable is continuous rather than ordinally discrete. Given the count nature of the data on the dependent variable, the use of either a Poisson or a Negative Binomial panel model suggests itself. In the context of count models the fixed effects cannot be swept out through transforming the count variable to group mean deviation form since such an approach in a non-linear setting does not remove the time-invariant heterogeneity and the resultant transformed variable is extremely unlikely to provide a count variable and hence be Poisson distributed.

The estimation of count models with fixed effects can be undertaken using either a conditional or an unconditional maximum likelihood estimator. ${ }^{12}$ The conditional maximum likelihood estimation procedure, as developed by Hausman, Hall and Grilliches (1984), conditions on the sum of the counts for an individual over time. The sum of counts follows a Poisson distribution if the underlying count data are also Poisson distributed. The resultant conditional likelihood function does not contain the fixed effects thus easing the estimation burden (see Greene (2000)). However, in contrast to the linear panel model, observations for players who incur no yellow cards during their presence in the panel are excluded given they make no contribution to the conditional maximum likelihood function. In contrast, the unconditional maximum likelihood approach of the Poisson panel is based on estimation of a regression model that includes the covariates and all individual player dummies. As long as this is practical given software constraints, it is econometrically feasible since the panel versions of these models are known not to suffer from the bias associated with the incidental parameters' problem. This 'brute force' approach also allows for the more direct retrieval of the fixed effects. As demonstrated by, for example, Cameron and Trivedi (2005), these two estimation methods yield identical estimates for the included covariates and the corresponding variance-covariance matrices. Thus, the choice of estimation method is largely motivated by computational convenience in any given application.

The Poisson panel regression model can be expressed as:

$\operatorname{Prob}\left(\mathrm{Y}_{\mathrm{it}}=\mathrm{y}_{\mathrm{it}}\right)=\frac{\mathrm{e}^{-\lambda_{\mathrm{it}} \lambda_{\mathrm{it}}^{\mathrm{yit}}}}{\mathrm{y}_{\mathrm{it}} !}$

with a common formulation for $\lambda_{\text {it }}$ given by the log-linear form for the $\mathrm{i}^{\text {th }}$ player at time $\mathrm{t}$ as:

\footnotetext{
${ }^{12}$ It is questionable whether the conditional maximum likelihood estimator for the fixed effects Negative Binomial model actually provides a valid fixed effects estimator (see Allison and Waterman (2002)).
} 
$\log \left(\lambda_{\mathrm{it}}\right)=\delta_{\mathrm{i}}+\mathbf{x}_{\mathrm{it}}^{\prime} \mathbf{b}$

where $x_{i t}$ is defined as above, $\mathbf{b}$ is the vector of unknown Poisson regression model estimates, and $\delta_{\mathrm{i}}$ is the fixed effect parameter for the $\mathrm{i}^{\text {th }}$ player. If a conditional estimator is used the $\mathrm{i}^{\text {th }}$ fixed effect could be retrieved as follows:

$\hat{\delta}_{\mathrm{i}}=\frac{1}{\mathrm{n}_{\mathrm{i}}} \sum_{\mathrm{t}=1}^{\mathrm{n}_{\mathrm{i}}}\left[\log \left(\lambda_{\mathrm{it}}\right)-\mathbf{\mathbf { x }}_{\mathrm{it}}^{\prime} \hat{\mathbf{b}}^{\mathrm{b}}\right]$

where $n_{i}$ is the sample size for the $i^{\text {th }}$ player. It is evident from expression [7] that the fixed effect is only estimable for those cases where the card count is non-zero. Thus, in contrast to the linear panel model in [1], cases where players record a zero card count across all time periods in the panel are excluded from the analysis, as indeed they are from the estimation procedure itself. If the unconditional estimator is used to estimate [6], then this involves inserting the full set of player-specific dummy variables in place of the constant term. Again, the estimated fixed effects are only meaningful for the sub-set of players that have received disciplinary cards. The corresponding standard errors are also easily retrievable within the unconditional framework as they are generated as part of the standard regression output.

A potential problem with the use of the Poisson model in this type of application relates to the empirical presence of an excess of zeros relative to what would be predicted by a Poisson distribution. The presence of excess zeros can induce over-dispersion in the data, a finding that sometimes prompts use of a Negative Binomial model. However, the motivation for use of the latter treats the source of the problem as individual heterogeneity rather than as a difference in the regime determining the zeros and the counts. ${ }^{13}$ In order to address the problem of excess zeros, a zero-inflated Poisson (ZIP) is estimated within a fixed effects framework. This type of model supplements the count density allowing a binary process to capture the probability of a zero outcome. The approach allows zeros to occur in two ways as a realization of the binary process and as a realisation of the count process when the binary random variable takes a value of one. The ZIP is interpretable as a compound Poisson and the binary process can be modelled using a standard logistic regression. The modification alters the Poisson formulation and relaxes the model's well known constraint that the mean and variance are equal.

\footnotetext{
${ }^{13}$ Mullahey (1986) highlights the interpretational and identification problems posed by excess zeros in the context of count models.
} 
The econometric approach favoured in the current study uses the unconditional maximum likelihood estimation of the Poisson and ZIP fixed effects models. ${ }^{14}$ The m estimable dummy variable fixed effects are retrieved for further analysis, and a second-stage regression containing the time invariant factors is expressed as:

$\hat{\delta}_{i}=\varphi+{ }_{\mathbf{z}_{i}^{\prime}}^{\prime} \phi+\mathrm{e}_{\mathrm{i}}$

where $\mathrm{z}$ is defined as above and $\mathrm{i}=1, \ldots \ldots \mathrm{m}<\mathrm{n}$

The estimated standard errors obtained for the Poisson fixed effects can be used to weight the fixed effects in the estimation of [8]. ${ }^{15}$

In order to complement our second-stage analysis, we also use a Weighted Least Absolute Deviations (WLAD) estimator for expressions [3] and [8] based on a median regression. The estimator is a special case of the quantile regression and is known to have better robustness properties relative to the least squares procedures (see Koenker (2005)). This approach is primarily undertaken to determine the sensitivity of the second-stage estimates to the presence of outliers in the distribution of the fixed effects.

We could treat the omitted factors as random rather than fixed, though this appears less plausible in the current context since we are using the population of Premiership footballers in our analysis. However, in such a treatment of the omitted factor a possible though imperfect choice could be a linear regression random effects model, which allows for the inclusion of time-invariant regressors like race and player position and is estimable by feasible generalised least squares (FGLS). Random effects estimators are also available for count models and, as in the case of the linear panel model, are less restrictive in terms of data constraints and the number of parameters estimated compared to their fixed effect counterparts. ${ }^{16}$ However, as in the case of the linear panel model, the orthogonality of the omitted factors with respect to the included covariates is required, which renders the

\footnotetext{
${ }^{14}$ We attempted to estimate unconditional Negative Binomial and Zero Inflated Negative Binomial fixed effects models but encountered a likelihood convergence failure in both cases.

${ }^{15}$ However, if these standard errors are not easily retrievable from the regression output, regression weights for the Poisson or ZIP fixed effects could be computed by $\overline{\mathbf{x}}_{\mathbf{i}}{ }^{\prime} \mathrm{V}(\hat{\mathbf{b}}) \overline{\mathbf{x}_{\mathbf{i}}}$ where $\mathrm{V}(\hat{\mathbf{b}})$ is the variance-covariance matrix corresponding to the covariate estimates in the relevant Poisson model and $\overline{\mathbf{x}_{i}}$ is vector of group means for the $\mathrm{i}^{\text {th }}$ player.

${ }^{16}$ If correctly specified the random effects model is more efficient than the fixed effects model and in the context of the Poisson has $\mathrm{m}$ additional degrees of freedom.
} 
approach potentially less attractive than the fixed effects estimator. In addition, an explicit distributional assumption for the random effects is also required. For the Poisson model, the characterisation of the random effects model is given by:

$\log \left(\lambda_{\mathrm{it}}\right)=\varepsilon_{\mathrm{i}}+\mathbf{x}_{\mathrm{it}}^{\prime} \mathbf{b}$

where $\varepsilon_{\mathrm{i}}$ denotes the random effect for the $\mathrm{i}^{\text {th }}$ player and $\exp \left(\varepsilon_{\mathrm{i}}\right)$ is assumed to follow a Gamma distribution. The assumption of normality for $\varepsilon_{\mathrm{i}}$ is also a feasible option but tends to be less tractable and more likely to encounter non-convergence problems in the maximisation of the log-likelihood function. Random effects can also be added to a Negative Binomial model under the assumption that the over-dispersion parameter is randomly distributed across players. The estimation of a random effects Negative Binomial model provides a less challenging exercise than its fixed effects counterpart (see footnote 14). The estimation procedure for the count models is conditional maximum likelihood with the random terms concentrated out of the likelihood function to facilitate estimation.

In order to complement our empirical findings using fixed effects models, we also estimate random effects models within linear, Poisson (both with Gamma and normally distributed random effects) and Negative Binomial frameworks with a view to comparing the time invariant covariates for these models with the corresponding set of estimates obtained using the second-stage weighted fixed effects regression models. It is an empirical question as to whether a random effects model is appropriate and whether its use is favoured over a fixed effects estimator. This is a testable proposition and will be the subject of investigation in the empirical analysis using standard Hausman tests where possible. ${ }^{17}$

\section{Empirical Results}

The estimated linear model with fixed effects provides the basis for a preliminary exploration of sanction outcomes. The specification includes controls for 30 Premiership clubs to capture the effects of different playing styles on sanctions. ${ }^{18}$ It also includes a set of time dummies for the relevant season to capture potential changes in refereeing policy within the Premiership over time. The average number of minutes played per game within a season is included to capture a player's exposure to the exercise of disciplinary sanctions by referees.

\footnotetext{
${ }^{17}$ Common problems encountered in the empirical implementation of the Hausman testing principle is either the negative definiteness or the singularity of the matrix of differences of the fixed and random effects variancecovariance matrices, either of which vitiates use of the matrix form of the test statistic.

${ }^{18}$ These vary over time given that players can potentially move from one Premiership club to another at the end of a season.
} 
The key driver for the application of sanctions is likely to be penalised foul play and thus the number of fouls called against a player per season features in the empirical specification. The linear panel model incorporates the 1,162 player-specific fixed effects.

The estimated results are reported in table $4 .{ }^{19}$ The goodness-of-fit is adequate by the standards of linear panel data models. There is evidence of a harsher application of the rules by referees over time. On average and ceteris paribus, the number of yellow cards issued rose by 0.7 of a card when the latest season (2007/08) is compared to the earliest season (2003/04). The estimated effect for minutes per game played is found to be positive and well determined though its magnitude is relatively small. The commission of an additional foul raises the disciplinary card count by 0.09 of a card, on average and ceteris paribus. As anticipated, this is an extremely well determined coefficient and, not surprisingly, the foul count variable explains well over one-half of the total variation in the number of yellow cards dispensed.

The unconditional maximum likelihood estimates for the fixed effects Poisson model are reported in the third column of table 4 . The estimates reveal that over one-quarter of the sample of players is lost in the implementation of this procedure given the inestimable nature of fixed effects for players with just one season of data. The signs and significance of the estimates are in line with those obtained for the linear panel model. However, the magnitudes of these estimates are not directly comparable to those reported for the linear panel model in this table. In order to translate the Poisson model estimates into comparable least squares marginal and impact effects, the coefficients require scaling by the grand mean value of the dependent variable. On the basis of the descriptive statistics reported in table 1, the relevant scaling factor is 2.2. The scaling does not yield dimensionally comparable estimates with the linear panel model, though the difference in magnitude is not substantial.

The logit specification for the ZIP model included a constant term, four controls for the relevant season, the age of the player at the start of the relevant season, fouls committed and the minutes played per game. ${ }^{20}$ The estimated effects for this model reported in the final

\footnotetext{
${ }^{19}$ The age of the player at the start of the relevant season does not feature as its inclusion prevented convergence of the fixed effects models. It also correlates with the league season dummy variables given that it is invariant within each season. In order to examine the age effect, the group average age of the player is included in the second-stage regression models using the fixed effects.

${ }^{20}$ The inclusion of club controls led to a failure in the convergence of the log-likelihood function for this model. However, all the regressors in the more austere logit specification used here were found to have well determined effects that were plausibly signed. The estimates for the logit model are available on request from the corresponding author.
} 
column of this table are broadly in comport with those obtained for the Poisson model and thus require little additional comment.

\section{Table 4 here}

The player-specific fixed effects are retrieved from the panel models reported in table 4 and plotted in figures 1 to 3 . These comprise 1,162 for the linear panel and 841 for the count models. An extreme observation was detected among the estimated fixed effects for the ZIP model and excluded from the analysis resulting in 840 individual effects for this particular model. The distribution of the fixed effects appears highly leptokurtic for the linear panel case and the Poisson model reveals evidence of a strong left-skewness. The assumption of normality in the distribution of the fixed effects is decisively rejected in all three cases. This is immaterial for the models estimating the fixed effects as no distributional assumption is required but may matter in the second-stage regression if normality violation reflects the role of outliers, for example. Table 5 reports the mean and median differences between 'white' and 'non-white' players in the estimated fixed effects and reveals for all three sets of fixed effects positive differentials in the disciplinary sanctions favouring 'white' players, which is redolent of the findings in table 3. The Mann-Whitney U-test confirms that the mean differentials in the estimated fixed effects are statistically significant in all three cases. However, the evidence in favour of statistically significant median differences appears considerably more marginal.

\section{Figures 1 to 3 and table 5 here}

The fixed effects are now used to formulate a second-stage regression model comprising the set of time invariant regressors. The second-stage models are estimated using WLS and given the presence of heteroscedasticity in all cases, the regression models' variancecovariance matrices are subject to the White (1980) correction. It should be noted that the group average age of a player is also included in this regression model to determine if age is an important determinant of sanction outcome (see footnote 19). The other variables included capture a player's field position, whether the player speaks English as their native language, and the set of racial affiliation variables with the 'white' category treated as the base group in estimation.

The first column of estimates in table 6 reports the WLS results for the linear panel model. The estimated model explains only $7.6 \%$ of the variation in the player fixed effects, so other 
unspecified factors are clearly important in determining sanction outcomes. ${ }^{21}$ The average age of the player exerts no independent effect on the outcome of interest and whether a player is a native English speaker also has no relevance. However, the field position of a player is important and the null hypothesis that a defender receives, on average and ceteris paribus, one yellow card more than a forward player cannot be rejected by the data in this case given the computed t-ratio of -0.41 . Midfield players and goalkeepers are also statistically more likely to incur the wrath of referees than forward players, though the latter result in regard to goalkeepers does appear counter-intuitive. Overall, the greater portion of the variation in the estimated fixed effects is explained by a player's field position. ${ }^{22}$ There appears to be a racial dimension to the application of sanctions with black and mixed race players receiving between a quarter and a third fewer yellow cards compared to white players, on average and ceteris paribus. Thus, there is no evidence on the basis of the linear panel model that ethnic minority players are treated unfairly by referees when controlling for match performance indicators and an array of other player and club characteristics. The proposition that referees are guided by a form of own-race bias in their sanction decision-making finds no support in these data. Taken at face value, using the linear panel model's fixed effects, there is some suggestive evidence that referees appear to behave more leniently towards players from these ethnic groups than towards own-race white players.

The interpretational narrative associated with the use of the Poisson and ZIP fixed effect WLS models shares some agreement with that presented for the linear model. It should be recalled that an extreme observation was removed from the ZIP regression model. ${ }^{23}$ Once scaled, the magnitudes of the estimated effects are broadly comparable. The substantive points of difference relate to a switch in sign on the goalkeeping position, the point estimates for which are now more plausibly signed as negative for the two count models though poorly determined in the ZIP model, and players with English as their native language are found to receive about a quarter of a card less compared to those who do not possess this attribute. However, this effect is only found to be well determined in the ZIP model. In regard to all three WLS mean regression models, the estimated effects for black and mixed race players are found not to be statistically distinguishable from one another with absolute asymptotic t-

\footnotetext{
${ }^{21}$ This perhaps confirms the perceptions of club coaches that there is a lot of noise in the process governing the use of yellow cards by referees.

${ }^{22}$ Approximately $90 \%$ of the variation in the fixed effects in the second-stage model is attributable to a player's field position in the team.

${ }^{23}$ The excluded estimated fixed effect for the ZIP model was in excess of 30 relative to a mean value of -0.29 . This places it sufficiently well outside the distribution of the fixed effects to merit exclusion from the subsequent analysis.
} 
ratios of $0.45,0.82$ and 0.53 for the linear, Poisson and ZIP WLS regression models. Thus, referee leniency appears unaffected by a player's skin shade and the classification of players into the 'white' and 'non-white' categories, as undertaken earlier in this paper to provide a summary descriptive analysis, appears justified ex-post.

\section{Table 6 here}

The violation of the normality assumption in the distribution of the fixed effects and the marginal results obtained in regard to median differences in the estimated fixed effects across broadly defined racial groups prompt further investigation of the robustness of the secondstage regression analysis. In particular, we are interested in determining the extent to which the mean regression findings of referee leniency towards non-white players in the application of the laws of the game is robust to the use of an alternative estimator. A weighted LAD (or median regression) estimator is used to estimate the determinants of the fixed effects and the results of this exercise are reported in table 7 . The fits of the median regression models are found to be poorer compared to the mean regressions reported in table 5, though the goodness-of-fit measures are not directly comparable given the different nature of their construction. In regard to the linear panel's fixed effects, the player position estimates retain statistical significance but only the mixed race effect is now well determined among the set of racial variables. However, in using the fixed effects based on count data models, none of the estimated race effects is found to achieve statistical significance at a conventional level either individually or jointly. ${ }^{24}$ This suggests that the negative racial effects noted earlier largely reflect the role of outliers in the mean regression. Thus, on the basis of the fixed effects estimates generated using the more appropriate econometric models for the task at hand, Premiership referees appear to have officiated in a race-neutral fashion over the five seasons subject to the analysis here.

\section{Table 7 here}

Finally, we now complement our results by examining a number of alternative mean-based econometric estimators that treat the unobservable factors as random rather than fixed. Although these are less challenging econometric models to estimate within a count framework compared to the unconditional fixed effects, they require a parametric distributional assumption for the individual random terms and moreover assume the

\footnotetext{
${ }^{24}$ The Wald tests for the joint significance of the three race variables in the WLAD models are 1.14 (probvalue $=0.77$ ) and 2.61 (prob-value $=0.46$ ) for the Poisson and ZIP fixed effects respectively.
} 
independence of the individual random effects from the covariates. In the three of four cases where the Hausman test can be computed, the null hypothesis of independence of random effects and covariates is rejected. In the fourth case, where the assumption of a normal distribution was used for the individual random effects, the Hausman test was not computable given singularity in the matrix of differences between the fixed and random effects variancecovariance matrices. Thus, on balance, the econometric evidence strongly favours use of the fixed effects estimators.

In spite of the findings of the Hausman test statistics, attention briefly turns to a discussion of the estimates for the random effects models. The first column of table 8 reveals a strong concordance between the estimates for the time invariant characteristics using the random effects model and those obtained using the WLS (mean) estimator of the fixed effects. Both sets of coefficients are dimensionally comparable and this is particularly evident in regard to the estimates for the race variables, the estimated effects for which are found to be well determined. The second column of estimates in table 8 is based on estimation of a random effects Poisson regression model under the assumption of Gamma distributed random effects (see Cameron and Trivedi (2005, p.802)). The estimates of the random effects model are invariant to incorporating an assumption of normality for the random effects as revealed in the penultimate column of this table. The final column provides estimates based on a Negative Binomial random effects model. ${ }^{25}$ On the basis of log-likelihood values, there is little that allows discrimination between the Poisson and the Negative Binomial random effects models, and the maximum likelihood estimates reported are almost indistinguishable. This is not surprising as the introduction of random effects into a Poisson model typically accounts for the effects of over-dispersion.

In regard to the estimated coefficients, the age effect is now found to be well determined and positive in the three count models suggesting older players receive more yellow cards. In addition, the estimated sign for the goalkeeper effect is reversed in contrast to the earlier findings for the linear panel random effects estimator. The estimates for the other field positions are broadly in line with the WLS estimates. The sign on the estimates for the racial variables mirror those from the linear panel model and once scaled the magnitudes are in broad comport with the linear panel estimates. However, the effects for black and mixed

\footnotetext{
${ }^{25}$ The Hausman test reported here is based on a comparison of the conditional Negative Binomial fixed effects model and the corresponding random effects model. The reservations of Allison and Waterman (2002) concerning the conditional fixed effects model remain apposite here.
} 
race, though remaining statistically significant at a conventional level, are found to be less precisely estimated compared to the findings from the less appropriate linear panel model.

\section{Table 8 about here}

\section{Conclusions}

This paper has examined the evidence for the existence of racial differences in the accumulation of disciplinary points in professional football using data drawn from five recent seasons of the English Premiership. A relatively rich data source (obtained from OPTA Sportsdata) was used to construct a unique dataset for the purpose of the study. The data have provide information on, inter alia, the player's age, club, field position, number of games played, time played per game, and on the number of yellow cards accumulated. These data were merged with data from other sources to identify a player's racial group across four separate categories (viz., white, black, mixed race, Asian).

The panel nature of the data was exploited to control for player-specific unobservables using a variety of panel estimators. The nature of the application and the econometric evidence favoured use of fixed rather than random effects estimators. The count data versions of these models, in conjunction with second-stage WLS and WLAD regressions, were selected as providing the preferred empirical approach. The key research question focused on racial differences in the receipt of sanctions and the econometric analysis yielded no evidence of an unfair treatment in the accumulation of disciplinary points by minority race players. The suggestive evidence of a greater leniency on the part of referees towards non-white players proved considerably less compelling in moving from the mean regression analysis of the fixed effects to the more appropriate median regression approach.

There is persuasive empirical evidence that referee behaviour along certain dimensions exhibits bias (e.g., see Dawson et al. (2007), Dohmen (2008) and Garicano et al. (2005)). However, our analysis suggests that this does not extend to an own-race bias. Premiership referees, who are all white with the sole exception of one who officiated in games in the first two seasons of our sample, display no evidence of a racial bias towards non-white players in the application of the rules of the game. This could be taken to reflect positively on the professional training of Premiership referees and the monitoring and evaluation procedures provided by the PGMOL. It may also reflect the fact that referee behaviour is heavily informed by the anti-racist initiatives that have characterised the professional game in 
England over the last decade or more. ${ }^{26}$ The issue of racism in professional football, and how it is tackled both on and off the field of play, has been a ubiquitous and recurring theme in the English game over the last 30 years. The fact that racist behaviour on the field of play can attract the ultimate sanction from a referee emphasizes how racially sensitive and aware referees have had to become over time, and this may explain the outcome observed in regard to disciplinary sanctions. Given the findings of Rickman and Witt (2008), we conjecture that the introduction of professional referees in 2001 may have acted to attenuate or even remove such bias in the highest echelon of the professional game. This is not an issue the current paper explicitly investigates given the data available post-date the advent of referee professionalism in 2001. However, the conjecture is not inconsistent with the findings of a study by Correll et al. (2006) on the weapons bias theme that demonstrated US police officers with the most firearms training exhibited the least race bias.

It is important to place the key results of this paper on race in context and provocatively take a less sanguine view of the findings reported. For instance, it may well be the case that the focus on cards rather than fouls acts to reduce the expression of implicit race bias on the part of referees given that a disciplinary card is dispensed after some deliberation and, in contrast to a foul call, well outside the time constraints of a split-second. However, it still remains an important finding that a player's race is not a determinant of a sanction outcome. Nevertheless, the finding that sanction and race are independent within the highest tier of the professional game in England may not generalise to other levels of the game in the country particularly given that refereeing in the lower divisions is undertaken on an amateur basis.

Our findings on race strongly contrast with the limited evidence available to date for the US. It is acknowledged that the methodology adopted here differs from that used by Price and Wolfers (2007), and it is also recognised that the structure and nature of refereeing in the professional soccer game in England does not permit a straight-forward application of their approach. However, shifting the focus from the player to the game played as the unit of observation, thus allowing for the control of referee and game effects, could potentially provide additional and richer insights on the determinants of sanction outcomes in professional soccer in England. Such an approach would also facilitate an analysis of, inter alia, the effects of league position, a home or away fixture, crowd attendance, and derby

\footnotetext{
${ }^{26}$ For example, the 'kick racism out of football' initiative was started in the early 1990 s but since the turn of the century has had the support of the Football Association, the Premiership League and its constituent clubs, and the Football Foundation.
} 
games on disciplinary outcomes, and also permit ordinal modelling of disciplinary sanctions across no card, yellow card and red card outcomes. This provides a significant part of the agenda for future research on this topic.

Finally, our two-stage empirical approach highlighted the feasibility of extracting information on time invariant factors while staying within a fixed effects framework. This is particularly important if the assumptions underlying the use of a random effects' estimator are vitiated and the policy focus is centred on time invariant factors like race or gender, for example. The second-stage regression procedure used does require a careful consideration of the empirical distribution of the fixed effects and use of the sampling variances for the estimated fixed effects is encouraged to enhance the econometric efficiency of the estimates. 


\section{References}

Ackerlof, G.A. (1980) A Theory of Social Custom of Which Unemployment May be One Outcome. Quarterly Journal of Economics, 94, 749-775.

Allison, P.D. and Waterman, R. P. (2002) Fixed Effects Negative Binomial Regression Models. Sociological Methodology, 32, 247-265.

Antonovics, D. and Knight, B. (2004) A New Look at Racial Profiling: Evidence from the Boston Police Department, NBER Working Paper 10634.

Becker, G. (1971) The Economics of Discrimination, Revised Edition, University of Chicago Press.

Bernheim, D.B. (1994) A Theory of Conformity, Journal of Political Economy, 102, 841877.

Bertrand, M., Chugh, D. and Mullainathan, S. (2005), Implicit Discrimination, American Economic Review, Papers \& Proceedings, 95, 94-98.

Cameron. A.C. and Trivedi, P. K. (2005) Microeconometrics: Methods and Applications, Cambridge University Press.

Conover, W.J. (1999) Practical Nonparametric Statistics, Third Edition, Wiley Series in Probability and Statistics.

Correll, J., Urland, G.L., and Ito, T. A. (2006) Event-related Potentials and the Decision to Shoot: The Role of Threat Perception and Cognitive Control, Journal of Experimental Psychology, 42, 120-128.

Dawson, P., Dobson, S., Goddard, J. and Wilson, J. (2007) Are football Referees Really Biased and Inconsistent? Evidence on the Incidence of Disciplinary Sanction in the English Premier League, Journal of the Royal Statistical Society, Series A, 170, 231-250.

Dohmen, T.J (2008) The Influence of Social Forces: Evidence from the Behaviour of Football Referees, Economic Inquiry, 46, 411-424.

Donohue, J. and Levitt, S. (2001) The Impact of Race on Policing and Arrests, Journal of Law and Economics, 44, 367 - 394.

Frick, B. (2007) The Football Players' Labor Market: Empirical Evidence from the Major European Leagues, Scottish Journal of Political Economy, 54, 422-446.

Garicano, L., Palacios-Huerta, I., and Prendergast, C. (2005) Favouritism under Social Pressure, Review of Economics and Statistics, 87, 208-216.

Gius, M. and Johnson, D. (2000) Race and Compensation in Professional Football, Applied Economics Letters, 7, 73-75. 
Goddard, J. and Wilson, J. O. N. (2009) Racial Discrimination in English Professional Football: Evidence from an Empirical Analysis of Players' Career Progression' Cambridge Journal of Economics, 33, 295-316.

Goldsmith, A.H., Hamilton, D and Darity, W. (2006) Shades of Discrimination: Skin Tone and Wages, American Economic Review, Papers \& Proceedings, 96, 242-245.

Greene, W.H. (2000) Econometric Analysis, Fourth Edition, Prentice Hall.

Hausman, G., Hall, B. and Grilliches, Z. (1984) Economic Models for Count Data with an Application to the patents and R \& D Relationship, Econometrica, 52, 1-28.

Kahn, L.M. (1991) Discrimination in Professional Sports: A Survey of the Literature, Industrial and Labor Relations Review, 44, 395-418.

Kahn, L.M. (2000) The Sports Business as a Labor Market Laboratory, Journal of Economic Perspectives, 14, 75-94.

Koenker, R. (2005) Quantile Regression, Econometric Society Monographs, Cambridge University Press.

Lucifora, C. and Simmons, R. (2003) Superstar Effects in Sports: Evidence from Italian Soccer. Journal of Sports Economics, 4, 35-55.

Medcalfe, S. (2008) English League Transfer Prices: Is There a Racial Dimension? A Reexamination with New Data, Applied Economics Letters, 15, 865 - 867.

Mullahey, J. (1986) Specification and Testing of some Modified Count Data Models, Journal of Econometrics, 33, 341-365.

Payne, B.K. (2006) Weapon Bias: Split-second Decisions and Unintended Stereotyping, Current Directions in Psychological Science, 15, 287-291.

Payne, B.K., Lambert, A. and Jacoby, L. (2002) Best Laid Plans: Effects of Goals and Accessibility Bias and Cognitive Control in Race-based Misperceptions of Weapons, Journal of Experimental Social Psychology, 38, 384-396.

Price, J. and Wolfers, J. (2007) Racial Discrimination among NBA Referees, NBER Working Paper Series, Working Paper \# 13206, National Bureau of Economic Research, Cambridge, Massachusetts.

Preston, I. and Szymanski, S. (2000) Racial Discrimination in English football, Scottish Journal of Political Economy, 47, 342-363.

Reilly, B. and Witt, R. (1995) English league transfer prices: is there a racial dimension?' Applied Economics Letters, 2, 220-222.

Rickman, N. and Witt, R. (2008) Favouritism and Financial Incentives: A Natural Experiment, Economica, 75, 296-309. 
Ridder, G., Cramer, J.S., and Hopstaken, P. (1994) Down to Ten: Estimating the Effect of a Red Card in Soccer, Journal of the American Statistical Association, 89, 1124-1127.

Rosen, S. and Sanderson, A. (2001) Labour Markets in Professional Sports, The Economic Journal, 111, F47-F68.

Stauffer, J.M. and Buckley, M. R. (2005) The Existence of Nature and Racial Bias in Supervisory Ratings, Journal of Applied Psychology, 90, 586-591.

Stoll, M., Raphael, S. and Holzer, H. (2004) Black Job Applicants and the Hiring Officer's Race, Industrial and Labor Relations Review, 57, 267-287.

Szymanski, S. (2000) A Market Test for Discrimination in the English Professional Soccer Leagues, Journal of Political Economy, 108, 590-603.

White, H. (1980) A Heteroscedastic-consistent Covariance Matrix Estimator and a Direct Test for Heteroscedasticity, Econometrica, 48, 817-838.

Witt, R. (2005) Do players React to Sanction Changes? Evidence from the English Premier League, Scottish Journal of Political Economy, 52, 623-640. 
Table 1: Variable Descriptions and Summary Statistics

\begin{tabular}{|c|c|c|c|}
\hline Variable Name & Variable Description & $\begin{array}{l}\text { Summary } \\
\text { Statistics } \\
\text { using } \\
\text { Panel } \\
\end{array}$ & $\begin{array}{l}\text { Summary } \\
\text { Statistics } \\
\text { using } \\
\text { Players }\end{array}$ \\
\hline Cards & $\begin{array}{l}\text { The number of yellow cards received by a player } \\
\text { in a given season. }\end{array}$ & $\begin{array}{r}2.1811 \\
(2.402)\end{array}$ & $\begin{array}{l}1.8225 \\
(1.940)\end{array}$ \\
\hline Season $2003 / 04$ & $\begin{array}{l}=1 \text { if observation relates to the } 2003 / 04 \\
\text { Premiership season, }=0 \text { otherwise. }\end{array}$ & 0.1963 & 0.2228 \\
\hline Season $2004 / 05$ & $\begin{array}{l}=1 \text { if observation relates to the } 2004 / 05 \\
\text { Premiership season, }=0 \text { otherwise. }\end{array}$ & 0.1955 & 0.1803 \\
\hline Season $2005 / 06$ & $\begin{array}{l}=1 \text { if observation relates to the } 2005 / 06 \\
\text { Premiership season, }=0 \text { otherwise. }\end{array}$ & 0.2035 & 0.1760 \\
\hline Season $2006 / 07$ & $\begin{array}{l}=1 \text { if observation relates to the } 2006 / 07 \\
\text { Premiership season, }=0 \text { otherwise. }\end{array}$ & 0.2027 & 0.1970 \\
\hline Season $2007 / 08$ & $\begin{array}{l}=1 \text { if observation relates to the } 2007 / 08 \\
\text { Premiership season, }=0 \text { otherwise. }\end{array}$ & 0.2020 & 0.2239 \\
\hline Fouls & $\begin{array}{l}\text { The total number of fouls committed by the } \\
\text { player in given season. }\end{array}$ & $\begin{array}{c}20.075 \\
(18.499)\end{array}$ & $\begin{array}{l}16.952 \\
(15.689)\end{array}$ \\
\hline $\begin{array}{l}\text { Minutes Played per } \\
\text { Game }\end{array}$ & $\begin{array}{l}\text { The number of minutes per game played by the } \\
\text { player in a given season. }\end{array}$ & $\begin{array}{l}66.699 \\
(22.283)\end{array}$ & $\begin{array}{l}62.764 \\
(22.337)\end{array}$ \\
\hline Age & $\begin{array}{l}\text { The age in years of the player at the start of the } \\
\text { relevant season. }\end{array}$ & $\begin{array}{l}26.138 \\
(4.594)\end{array}$ & $\begin{array}{l}25.912 \\
(4.688)\end{array}$ \\
\hline Native Speaker & $\begin{array}{l}=1 \text { if the player is a native English speaker based } \\
\text { on their country of origin, }=0 \text { otherwise. }\end{array}$ & 0.6188 & 0.5860 \\
\hline Goalkeeper & $=1$ if the player is a goalkeeper, $=0$ otherwise. & 0.0847 & 0.0852 \\
\hline Defender & $=1$ if the player is a defender, $=0$ otherwise. & 0.3417 & 0.3322 \\
\hline Midfielder & $=1$ if the player is a midfielder, $=0$ otherwise. & 0.3508 & 0.3477 \\
\hline Forward & $=1$ if the player is a forward, $=0$ otherwise. & 0.2228 & 0.2349 \\
\hline Asian & $=1$ if the player is Asian, $=0$ otherwise. & 0.0083 & 0.0086 \\
\hline Black & $=1$ if the player is black, $=0$ otherwise. & 0.1796 & 0.1738 \\
\hline Mixed & $=1$ if the player is mixed race, $=0$ otherwise. & 0.1424 & 0.1472 \\
\hline White & $=1$ if the player is white,$=0$ otherwise. & 0.6697 & 0.6704 \\
\hline
\end{tabular}

Notes to table 1: (a) The total sample of 2634 observations on 1162 players is used in the calculation of the summary statistics. (b) The number of observations per player is 2.3. (c) Standard errors are reported in parentheses for the continuous measures only. (d) The 30 premiership clubs for the five seasons are: Arsenal, Aston Villa, Birmingham City, Blackburn Rovers, Bolton, Charlton Athletic, Crystal Palace, Chelsea, Derby County, Everton, Fulham, Liverpool, Leeds United, Leicester, Manchester United, Manchester City, Middlesboro, Newcastle United, Norwich City, Portsmouth, Reading, Sheffield United, Southampton, Sunderland, Tottenham Hotspur, Watford, West Bromwich Albion, West Ham United, Wigan Athletic, Wolverhampton Wanderers. 
Table 2: Fouls Penalised by Broadly Defined Racial Groups

\begin{tabular}{l|l|l|l|l|l|l}
\hline Season & $\begin{array}{l}\text { Average } \\
\text { Foul Count } \\
\text { for } \\
\text { Non-White } \\
\text { Players }\end{array}$ & $\begin{array}{l}\text { Average } \\
\text { Foul Count } \\
\text { for White } \\
\text { Players }\end{array}$ & t-test & $\begin{array}{l}\text { Mann- } \\
\text { Whitney } \\
\text { U-Test }\end{array}$ & $\begin{array}{l}\text { Median } \\
\text { Test }\end{array}$ & $\begin{array}{l}\text { Sample } \\
\text { Size }\end{array}$ \\
\hline $2003 / 04$ & 21.56 & 20.37 & $\begin{array}{l}0.646 \\
(0.518)\end{array}$ & $\begin{array}{l}0.948 \\
(0.323)\end{array}$ & $\begin{array}{c}0.765 \\
(0.382)\end{array}$ & 517 \\
\hline $2004 / 05$ & 22.75 & 20.23 & $\begin{array}{l}1.395 \\
(0.164)\end{array}$ & $\begin{array}{l}1.548 \\
(0.122)\end{array}$ & $\begin{array}{l}0.547 \\
(0.459)\end{array}$ & 515 \\
\hline $2005 / 06$ & 22.04 & 19.53 & $\begin{array}{l}1.438 \\
(0.151)\end{array}$ & $\begin{array}{l}1.619 \\
(0.106)\end{array}$ & $\begin{array}{c}0.915 \\
(0.339)\end{array}$ & 536 \\
\hline $2006 / 07$ & 21.56 & 18.29 & $\begin{array}{l}2.012 \\
(0.045)\end{array}$ & $\begin{array}{l}2.772 \\
(0.006)\end{array}$ & $\begin{array}{c}4.716 \\
(0.030)\end{array}$ & 534 \\
\hline $2007 / 08$ & 19.74 & 18.42 & $\begin{array}{l}0.833 \\
(0.405)\end{array}$ & $\begin{array}{l}0.628 \\
(0.530)\end{array}$ & $\begin{array}{c}0.612 \\
(0.434)\end{array}$ & 532 \\
\hline All Seasons & 21.436 & 19.405 & $\begin{array}{l}2.653 \\
(0.010)\end{array}$ & $\begin{array}{l}3.224 \\
(0.001)\end{array}$ & $\begin{array}{c}5.529 \\
(0.019)\end{array}$ & 2634 \\
\hline
\end{tabular}

Notes to table 2: (a) The parametric t-tests are based on assuming equal variances. (b) The non-parametric Mann-Whitney U test is distributed as $\mathrm{N}(0,1)$. (c) Median test is computed using Conover (1999, pp.218-220) and is distributed as a chisquared with one degree of freedom. (d) Prob-values are reported in parentheses for the test statistics.

Table 3: Cards Received by Broadly Defined Racial Groups

\begin{tabular}{l|l|l|l|l|l|l}
\hline Season & $\begin{array}{l}\text { Average } \\
\text { Yellow } \\
\text { Cards for } \\
\text { Non-White } \\
\text { Players }\end{array}$ & $\begin{array}{l}\text { Average } \\
\text { Yellow } \\
\text { Cards for } \\
\text { White } \\
\text { Players }\end{array}$ & t-test & $\begin{array}{l}\text { Mann- } \\
\text { Whitney } \\
\text { U-Test }\end{array}$ & $\begin{array}{l}\text { Median } \\
\text { Test }\end{array}$ & $\begin{array}{l}\text { Sample } \\
\text { Size }\end{array}$ \\
\hline $2003 / 04$ & 1.97 & 2.21 & $\begin{array}{l}-0.98 \\
(0.33)\end{array}$ & $\begin{array}{l}-0.89 \\
(0.37)\end{array}$ & $\begin{array}{l}2.54 \\
(0.11)\end{array}$ & 517 \\
\hline $2004 / 05$ & 1.89 & 2.00 & $\begin{array}{l}-0.51 \\
(0.61)\end{array}$ & $\begin{array}{l}-0.07 \\
(0.95)\end{array}$ & $\begin{array}{l}0.14 \\
(0.70)\end{array}$ & 515 \\
& & 2.30 & -1.61 & -1.15 & 1.53 & 536 \\
$(0.11)$ & $(0.25)$ & $(0.21)$ & \\
\hline $2005 / 06$ & 1.94 & 2.37 & -0.84 & 0.16 & 0.03 & 534 \\
& & $(0.40)$ & $(0.87)$ & $(0.84)$ & \\
\hline $2006 / 07$ & 2.19 & 2.34 & -0.60 & -0.69 & 0.79 & 532 \\
& & $(0.55)$ & $(0.49)$ & $(0.38)$ & \\
\hline $2007 / 08$ & 2.21 & 2.24 & -1.86 & -0.99 & 0.82 & 2634 \\
& & $(0.06)$ & $(0.32)$ & $(0.37)$ & \\
\hline All Seasons & 2.06 & 2.24 & &
\end{tabular}

Notes to table 3: See Notes to table 2. 
Table 4: Fixed Effects Model for Number of Cards Received

\begin{tabular}{|c|c|c|c|}
\hline Variables & Linear & Poisson & $\begin{array}{l}\text { Zero Inflated } \\
\text { Poisson (ZIP) } \\
\end{array}$ \\
\hline Season $2003 / 04$ & $\dagger$ & $\dagger$ & $\dagger$ \\
\hline Season $2004 / 05$ & $\begin{array}{l}-0.0944 \\
(0.1219)\end{array}$ & $\begin{array}{l}-0.0714 \\
(0.0513)\end{array}$ & $\begin{array}{l}-0.0538 \\
(0.0525)\end{array}$ \\
\hline Season $2005 / 06$ & $\begin{array}{c}0.2259 * \\
(0.1329) \\
\end{array}$ & $\begin{array}{c}0.0507 \\
(0.0524) \\
\end{array}$ & $\begin{array}{c}0.0530 \\
(0.0536) \\
\end{array}$ \\
\hline Season $2006 / 07$ & $\begin{array}{l}0.5819 * * * \\
(0.1482)\end{array}$ & $\begin{array}{l}0.2274 * * * \\
(0.0551)\end{array}$ & $\begin{array}{l}0.2091 * * * \\
(0.0565)\end{array}$ \\
\hline Season $2007 / 08$ & $\begin{array}{l}0.6962 * * * \\
(0.1577)\end{array}$ & $\begin{array}{l}0.2680^{* * *} \\
(0.0582)\end{array}$ & $\begin{array}{l}0.2487 * * * \\
(0.0595)\end{array}$ \\
\hline Fouls & $\begin{array}{l}0.0879 * * * \\
(0.0048)\end{array}$ & $\begin{array}{l}0.0284 * * * \\
(0.0016)\end{array}$ & $\begin{array}{l}0.0272 * * * \\
(0.0017)\end{array}$ \\
\hline Minutes Played per Game & $\begin{array}{l}0.0065^{* *} \\
(0.0031)\end{array}$ & $\begin{array}{l}0.0114 * * * \\
(0.0019)\end{array}$ & $\begin{array}{l}0.0079 * * * \\
(0.0021)\end{array}$ \\
\hline Club Controls Included & Yes & Yes & Yes \\
\hline Total Sample Size & 2634 & 1793 & 1793 \\
\hline Number of Players & 1162 & 841 & 841 \\
\hline $\mathrm{R}^{2}-$ Within & 0.4079 & $\mathrm{n} / \mathrm{a}$ & $\mathrm{n} / \mathrm{a}$ \\
\hline Log-Likelihood Value & -3909.1 & -3259.7 & -3287.9 \\
\hline
\end{tabular}

Notes to table 4: (a) $* * *, * *$ and $*$ denotes statistical significance at the $0.1,0.05$ and 0.01 levels respectively. (b) The number of premiership club controls included is 29 with one arbitrarily dropped as the base (see notes to table 1 for the list of clubs). (c) $\dagger$ denotes base group in estimation. (d) The Poisson and ZIP models are based on maximising the unconditional log-likelihood function.

Table 5: Differences in Estimated Fixed Effects between 'White' and 'Non-white' Players

\begin{tabular}{l|l|l|l|l|l|l}
\hline Variables & $\begin{array}{l}\text { Sample } \\
\text { Size }\end{array}$ & $\begin{array}{l}\text { Mean } \\
\text { Difference }\end{array}$ & $\begin{array}{l}\text { Median } \\
\text { Difference }\end{array}$ & $\begin{array}{l}\text { Normality } \\
\text { Test }\end{array}$ & $\begin{array}{l}\text { Mann- } \\
\text { Whitney } \\
\text { U test }\end{array}$ & $\begin{array}{l}\text { Median } \\
\text { Test }\end{array}$ \\
\hline Linear & 1162 & 0.248 & 0.150 & 117.6 & -3.06 & 3.05 \\
& & $(0.082)$ & $(0.079)$ & $(0.000)$ & $(0.002)$ & $(0.081)$ \\
\hline Poisson & 841 & 0.106 & 0.093 & 48.33 & -2.02 & 1.94 \\
& & $(0.046)$ & $(0.063)$ & $(0.000)$ & $(0.043)$ & $(0.164)$ \\
\hline Zero Inflated & 840 & 0.105 & 0.100 & 50.50 & -2.26 & 3.63 \\
Poisson (ZIP) & & $(0.045)$ & $(0.052)$ & $(0.00)$ & $(0.024)$ & $(0.060)$ \\
\hline
\end{tabular}

Notes to table 5: (a) The Normality test is based on the Bera-Jarque test for skewness and kurtosis and uses the full sample of fixed effects. (b) The mean and median differences refer to the mean and median differences in estimated fixed effects between the 'white' and 'non-white' groups. (c) The non-parametric Mann-Whitney U-test is distributed as N(0,1) and tests for rank differences in estimated fixed effects between 'white' and 'non-white' groups. (d) The median test is computed using Conover (1999, pp.218-220), is distributed as a chi-squared with one degree of freedom and tests for median differences in estimated fixed effects between 'white' and 'non-white' groups. (e) Prob-values are reported in parentheses for the test statistics and the estimated standard errors for the mean and median point differences reported in parentheses are based on the estimation respectively of mean and median regressions of the fixed effects on the 'white' dummy variable only. 
Table 6: Cards Received and Time Invariant Factors (WLS)

\begin{tabular}{l|l|l|l}
\hline Variables & $\begin{array}{l}\text { Weighted Least } \\
\text { Squares using } \\
\text { Linear Model } \\
\text { Fixed Effects }\end{array}$ & $\begin{array}{l}\text { Weighted Least } \\
\text { Squares using } \\
\text { Poisson Model } \\
\text { Fixed Effects }\end{array}$ & $\begin{array}{l}\text { Weighted Least } \\
\text { Squares using } \\
\text { Zero Inflated } \\
\text { Poisson Model } \\
\text { Fixed Effects }\end{array}$ \\
\hline Constant & $-1.7485^{* * *}$ & $-1.2726^{* * *}$ & $-0.9811^{* * *}$ \\
& $(0.2532)$ & $(0.1254)$ & $(0.1444)$ \\
\hline Age & 0.0063 & 0.0047 & 0.0015 \\
& $(0.0085)$ & $(0.0042)$ & $(0.0049)$ \\
\hline Native English & 0.0198 & -0.0259 & $-0.0864^{* *}$ \\
Speaker & $(0.0776)$ & $(0.0371)$ & $(0.0423)$ \\
\hline Goalkeeper & $0.4139^{* * *}$ & $-0.2945^{* *}$ & -0.1710 \\
& $(0.1222)$ & $(0.1748)$ & $(0.1108)$ \\
\hline Defender & $0.9566^{* * *}$ & $0.1767^{* * *}$ & $0.2531^{* * *}$ \\
& $(0.1062)$ & $(0.0551)$ & $0.0597)$ \\
\hline Midfielder & $0.8083^{* * *}$ & $0.1979^{* * *}$ & $0.2222^{* * *}$ \\
& $(0.1072)$ & $(0.0538)$ & $(0.0574)$ \\
\hline Forward & $\dagger$ & $\dagger$ & $\dagger$ \\
\hline Asian & -0.2952 & -0.1959 & -0.1169 \\
& $(0.1838)$ & $(0.1720)$ & $(0.1456)$ \\
\hline Black & $-0.2594^{* *}$ & $-0.1441^{* * *}$ & $-0.1710^{* * *}$ \\
& $(0.1039)$ & $(0.0517)$ & $(0.0588)$ \\
\hline Mixed Race & $-0.3178^{* * *}$ & $-0.0917 *$ & $-0.1311^{* *}$ \\
& $(0.0973)$ & $(0.0497)$ & $(0.0585)$ \\
\hline White & $\dagger$ & $\dagger$ & + \\
\hline Sample Size & 1162 & 841 & 0.0633 \\
\hline $\mathrm{R}^{2}$ & 0.0753 & 0.0677 & 0 \\
\hline
\end{tabular}

Notes to table 6: (a) $* * *, * *$ and $*$ denotes statistical significance at the $0.1,0.05$ and 0.01 levels respectively. (b) $\dagger$ denotes omitted category in estimation. (c) The Breusch-Pagan tests for homoscedasticity with 8 degrees of freedom are 53.4, 32.0 and 32.4 for the linear, Poisson and ZIP fixed effects respectively. (d) Given heteroscedasticity in all cases, White (1980) standard errors are reported in parentheses. (e) The $\mathrm{R}^{2}$ values reported are based on the squared correlation coefficient between the actual and predicted values. 
Table 7: Yellow Cards Received and Time Invariant Factors (WLAD)

\begin{tabular}{|c|c|c|c|}
\hline Variables & $\begin{array}{l}\text { Weighted LAD } \\
\text { using Linear } \\
\text { Model Fixed } \\
\text { Effects }\end{array}$ & $\begin{array}{l}\text { Weighted LAD } \\
\text { using Poisson } \\
\text { Model Fixed } \\
\text { Effects }\end{array}$ & $\begin{array}{l}\text { Weighted LAD } \\
\text { using Zero } \\
\text { Inflated Poisson } \\
\text { Model Fixed } \\
\text { Effects }\end{array}$ \\
\hline Constant & $\begin{array}{l}-1.7942 \\
(0.2309)\end{array}$ & $\begin{array}{l}-1.5850^{* * *} \\
(0.1968)\end{array}$ & $\begin{array}{l}-1.2589 * * * \\
(0.1553)\end{array}$ \\
\hline Age & $\begin{array}{c}0.0088 \\
(0.0079) \\
\end{array}$ & $\begin{array}{r}0.0121^{*} \\
(0.0069)\end{array}$ & $\begin{array}{c}0.0083 \\
(0.0054) \\
\end{array}$ \\
\hline $\begin{array}{l}\text { Native English } \\
\text { Speaker }\end{array}$ & $\begin{array}{c}0.0518 \\
(0.0763)\end{array}$ & $\begin{array}{l}-0.0507 \\
(0.0559)\end{array}$ & $\begin{array}{l}-0.0009 \\
(0.0532) \\
\end{array}$ \\
\hline Goalkeeper & $\begin{array}{c}0.1643 \\
(0.1049)\end{array}$ & $\begin{array}{l}-0.5454 * * * \\
(0.1838)\end{array}$ & $\begin{array}{l}-0.2083 \\
(0.1395)\end{array}$ \\
\hline Defender & $\begin{array}{l}0.4977^{* * * *} \\
(0.1040)\end{array}$ & $\begin{array}{l}0.2804 * * * \\
(0.0757)\end{array}$ & $\begin{array}{l}0.3252^{* * * *} \\
(0.0676)\end{array}$ \\
\hline Midfielder & $\begin{array}{l}0.5869 * * * \\
(0.1032)\end{array}$ & $\begin{array}{l}0.2496^{* * * *} \\
(0.0681)\end{array}$ & $\begin{array}{l}0.2762^{* * * *} \\
(0.0735)\end{array}$ \\
\hline Forward & $\dagger$ & $\dagger$ & $\dagger$ \\
\hline Asian & $\begin{array}{l}-0.1051 \\
(0.3421) \\
\end{array}$ & $\begin{array}{l}-0.1021 \\
(0.2802)\end{array}$ & $\begin{array}{l}-0.0864 \\
(0.2536) \\
\end{array}$ \\
\hline Black & $\begin{array}{l}-0.0733 \\
(0.1217)\end{array}$ & $\begin{array}{l}-0.0705 \\
(0.0790) \\
\end{array}$ & $\begin{array}{l}-0.0754 \\
(0.0580)\end{array}$ \\
\hline Mixed Race & $\begin{array}{l}-0.2585^{* * *} \\
(0.1129)\end{array}$ & $\begin{array}{l}-0.0552 \\
(0.0822) \\
\end{array}$ & $\begin{array}{l}-0.1005 \\
(0.0770) \\
\end{array}$ \\
\hline White & $\dagger$ & $\dagger$ & $\dagger$ \\
\hline Sample Size & 1162 & 841 & 840 \\
\hline Pseudo-R ${ }^{2}$ & 0.0264 & 0.0420 & 0.0405 \\
\hline
\end{tabular}

Notes to table 7: (a) ${ }^{* * *}, * *$ and $*$ denotes statistical significance at the $0.1,0.05$ and 0.01 levels respectively. (b) $\dagger$ denotes omitted category in estimation (c) The estimated standard errors are based on the bootstrapping technique with 200 replications. (d) The Pseudo- $\mathrm{R}^{2}$ values reported are based on use of the following formula: $1-$ minimized sum of absolute weighted deviations . raw sum of absolute weighted deviations

Table 8: Cards Received using Random Effects Models 


\begin{tabular}{|c|c|c|c|c|}
\hline Variables & $\begin{array}{l}\text { Linear } \\
\text { (Gaussian } \\
\text { Distributed } \\
\text { Random } \\
\text { Effects) }\end{array}$ & $\begin{array}{l}\text { Poisson } \\
\text { (Gamma } \\
\text { Distributed } \\
\text { Random } \\
\text { Effects) }\end{array}$ & $\begin{array}{l}\text { Poisson } \\
\text { (Normally } \\
\text { Distributed } \\
\text { Random } \\
\text { Effects) }\end{array}$ & $\begin{array}{l}\text { Negative } \\
\text { Binomial } \\
\text { (Gamma } \\
\text { Distributed } \\
\text { Random } \\
\text { Effects) }\end{array}$ \\
\hline Constant & $\begin{array}{l}-0.7366^{* * *} \\
(0.2872)\end{array}$ & $\begin{array}{l}-1.4615 * * * \\
(0.1764)\end{array}$ & $\begin{array}{l}-1.5851^{* * *} \\
(0.1775)\end{array}$ & $\begin{array}{l}2.9339 \\
(2.7796)\end{array}$ \\
\hline Season 2003/04 & $\dagger$ & $\dagger$ & $\dagger$ & $\dagger$ \\
\hline Season $2004 / 05$ & $\begin{array}{l}-0.1204 \\
(0.1000)\end{array}$ & $\begin{array}{l}-0.0648 \\
(0.0532)\end{array}$ & $\begin{array}{l}-0.0628 \\
(0.0532)\end{array}$ & $\begin{array}{l}-0.0641 \\
(0.0538)\end{array}$ \\
\hline Season $2005 / 06$ & $\begin{array}{c}0.1383 \\
(0.1004)\end{array}$ & $\begin{array}{c}0.0377 \\
(0.0539)\end{array}$ & $\begin{array}{c}0.0390 \\
(0.0537)\end{array}$ & $\begin{array}{c}0.0387 \\
(0.0545)\end{array}$ \\
\hline Season $2006 / 07$ & $\begin{array}{l}0.4144 * * * \\
(0.1044)\end{array}$ & $\begin{array}{l}0.1824 * * * \\
(0.0527)\end{array}$ & $\begin{array}{l}0.1824 * * * \\
(0.0522)\end{array}$ & $\begin{array}{l}0.1825^{* * * *} \\
(0.0532)\end{array}$ \\
\hline Season $2007 / 08$ & $\begin{array}{l}0.4247 * * * \\
(0.1053)\end{array}$ & $\begin{array}{l}0.1934 * * * \\
(0.0566)\end{array}$ & $\begin{array}{l}0.1937 * * * \\
(0.0560)\end{array}$ & $\begin{array}{l}0.1940 * * * \\
(0.0571)\end{array}$ \\
\hline Fouls & $\begin{array}{l}0.0907 * * * \\
(0.0024)\end{array}$ & $\begin{array}{l}0.0304 * * * \\
(0.0010)\end{array}$ & $\begin{array}{l}0.0301 * * * \\
(0.0110)\end{array}$ & $\begin{array}{l}0.0304 * * * \\
(0.0010)\end{array}$ \\
\hline Minutes Played per Game & $\begin{array}{l}0.0046^{* *} \\
(0.0020)\end{array}$ & $\begin{array}{l}0.0127 * * * \\
(0.0014)\end{array}$ & $\begin{array}{l}0.0128 * * * \\
(0.0014)\end{array}$ & $\begin{array}{l}0.0127 * * * \\
(0.0014)\end{array}$ \\
\hline Age & $\begin{array}{c}0.0075 \\
(0.0084)\end{array}$ & $\begin{array}{l}0.0156^{* * *} \\
(0.0048)\end{array}$ & $\begin{array}{l}0.0160 * * * \\
(0.0050)\end{array}$ & $\begin{array}{l}0.0156^{* * *} \\
(0.0051)\end{array}$ \\
\hline Native English Speaker & $\begin{array}{l}-0.0045 \\
(0.0812)\end{array}$ & $\begin{array}{l}-0.0675 \\
(0.0450)\end{array}$ & $\begin{array}{l}-0.0738 \\
(0.0490)\end{array}$ & $\begin{array}{l}-0.0675 \\
(0.0501)\end{array}$ \\
\hline Goalkeeper & $\begin{array}{c}0.5323^{* *} \\
(0.1849)\end{array}$ & $\begin{array}{l}-0.8950 * * * \\
(0.3824)\end{array}$ & $\begin{array}{l}-0.9014 * * * \\
(0.1250)\end{array}$ & $\begin{array}{l}-0.9034 * * * \\
(0.1271)\end{array}$ \\
\hline Defender & $\begin{array}{l}1.0088^{* * * *} \\
(0.1131)\end{array}$ & $\begin{array}{l}0.3824 * * \\
(0.0655)\end{array}$ & $\begin{array}{l}0.4144 * * * \\
(0.0660)\end{array}$ & $\begin{array}{l}0.3848^{* * *} \\
(0.0670)\end{array}$ \\
\hline Midfielder & $\begin{array}{l}0.8058^{* * *} \\
(0.1020)\end{array}$ & $\begin{array}{l}0.3307 * * * \\
(0.0592)\end{array}$ & $\begin{array}{l}0.3607 * * * \\
(0.0559)\end{array}$ & $\begin{array}{l}0.3328 * * * \\
(0.0568)\end{array}$ \\
\hline Forward & $\dagger$ & $\dagger$ & $\dagger$ & $\dagger$ \\
\hline Asian & $\begin{array}{l}-0.2855 \\
(0.4046)\end{array}$ & $\begin{array}{l}-0.1308 \\
(0.2327)\end{array}$ & $\begin{array}{l}-0.1191 \\
(0.3004)\end{array}$ & $\begin{array}{l}-0.1330 \\
(0.3138)\end{array}$ \\
\hline Black & $\begin{array}{l}-0.1999 * * \\
(0.1015)\end{array}$ & $\begin{array}{l}-0.1080^{*} \\
(0.0562)\end{array}$ & $\begin{array}{l}-0.1044^{*} \\
(0.0589) \\
\end{array}$ & $\begin{array}{l}-0.1082^{*} \\
(0.0601)\end{array}$ \\
\hline Mixed Race & $\begin{array}{l}-0.2944 * * * \\
(0.1111)\end{array}$ & $\begin{array}{l}-0.1148^{*} \\
(0.0634) \\
\end{array}$ & $\begin{array}{l}-0.1093^{*} \\
(0.0656) \\
\end{array}$ & $\begin{array}{l}-0.1149^{*} \\
(0.0661) \\
\end{array}$ \\
\hline White & $\dagger$ & $\dagger$ & $\dagger$ & $\dagger$ \\
\hline Sample Size & 2634 & 2634 & 2634 & 2634 \\
\hline Random Effects $\sim \chi_{1}^{2}$ & $\begin{array}{c}334.3 \\
(0.000)\end{array}$ & $\begin{array}{c}306.3 \\
(0.000) \\
\end{array}$ & $\begin{array}{c}300.0 \\
(0.000)\end{array}$ & $\begin{array}{l}178.7 \\
(0.000)\end{array}$ \\
\hline Hausman Test $\sim \chi_{35}^{2}$ & $\begin{array}{c}66.4 \\
(0.001)\end{array}$ & $\begin{array}{c}61.3 \\
(0.004)\end{array}$ & $\begin{array}{l}\text { Not } \\
\text { Computable }\end{array}$ & $\begin{array}{l}51.3 \\
(0.037)\end{array}$ \\
\hline $\mathrm{R}^{2}$ or Pseudo- $\mathrm{R}^{2}$ & 0.5565 & 0.1729 & 0.1779 & 0.1677 \\
\hline Log-Likelihood Value & -3909.07 & -4159.92 & -4163.10 & -4159.85 \\
\hline \multicolumn{5}{|c|}{$\begin{array}{l}\text { Notes to table 8: (a) } * * *, * * \text { and } * \text { denotes statistical significance at the } 0.1,0.05 \text { and } 0.01 \text { levels respectively. (b) } \dagger \text { denotes } \\
\text { omitted category in estimation (c) The chi-squared tests for the presence of random effects are based on the Breusch-Pagan } \\
\text { test for the linear panel model, and on likelihood ratio tests based on a comparison of log-likelihood values for the count } \\
\text { random effects models (i.e., the unrestricted models) and their pooled alternatives (i.e., the restricted models). The null } \\
\text { hypothesis is that the variance of the random effects is zero, which provides the one restriction under test. (d) The } \mathrm{R}^{2} \text { value } \\
\text { computed for the linear panel model is the squared correlation coefficient between the actual and predicted values. The } \\
\text { McFadden- } \mathrm{R}^{2} \text { values are computed for the three maximum likelihood estimated models. (e) The Hausman test is testing for } \\
\text { the orthogonality of covariates and random effects. The test was not computable for the Poisson with normally distributed } \\
\text { random effects (see text). }\end{array}$} \\
\hline
\end{tabular}

Figure 1: Kernel Density Plot for Linear Panel Model Fixed Effects 


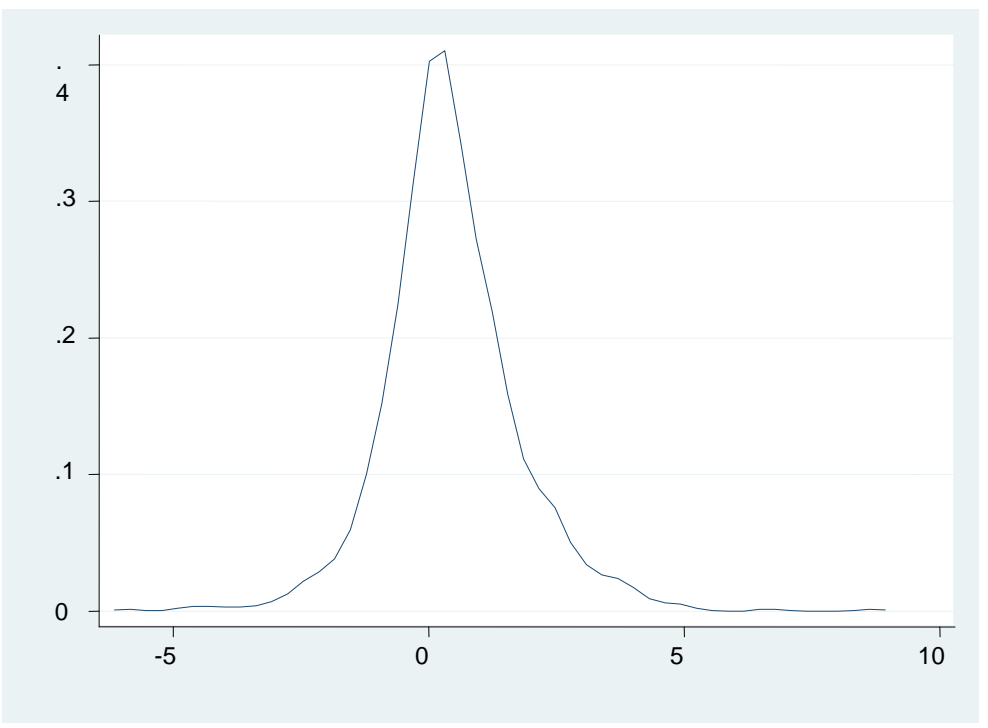

Figure 2: Kernel Density Plot for Poisson Model Fixed Effects

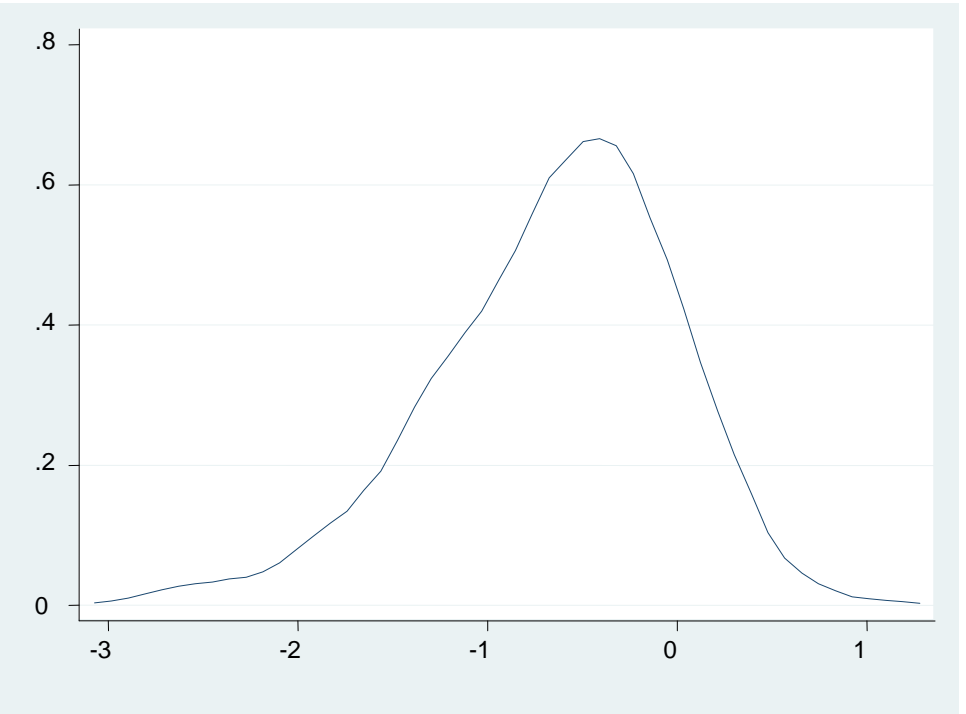

Figure 3: Kernel Density Plot for Zero Inflated Poisson (ZIP) Model Fixed Effects 


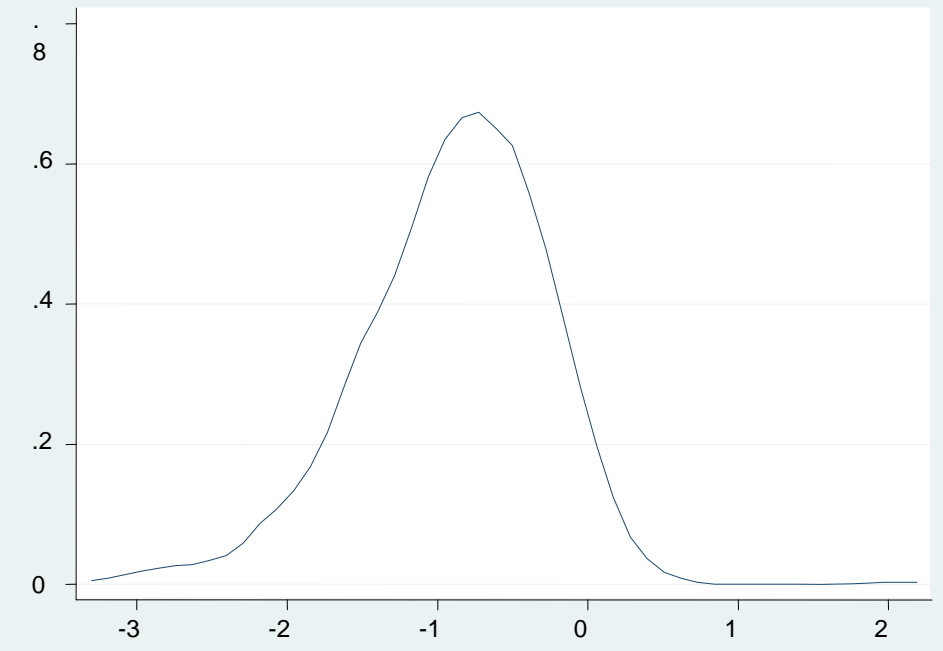

